\title{
A Study of Casual Relationship of Job Design and Employee's Behavior
}

\author{
Saqib Muneer ${ }^{1}$, Khalid Jamil2*, Muhammad Idrees² \\ ${ }^{1}$ University of hail, Hail, Saudi Arabia \\ ${ }^{2}$ Govt College University, Faisalabad, Pakistan \\ saqibmuneer85@gmail.com, khalidjamil29@yahoo.com,muhammadidreesmalik@yahoo.com
}

\begin{abstract}
Some factors other than higher salaries, compensation benefits and conducive workplace seem to have strong impact on employee's performance i.e. organization citizenship behavior and counterproductive work behavior. Purpose of this study is to examine the impact of job design elements i.e. job enlargement, job enrichment and job rotation on employee's organizational citizenship behavior and counterproductive work behavior in the banking sector of Faisalabad and extent to which this relationship is mediated by motivation. Data was collected from 170 frontline managers of banks. After analysis of data, it was found that that there is a positive and significant relationship between job enlargements, job enrichment on OCB while negative and significant relationship between job rotation and OCB. Negative and significant relationship between job enlargement and CWB, negative but insignificant relationship between job enrichment and CWB while positive and significant relationship was found between the job rotation and CWB. Motivation was partially mediating the relationship between job enlargement, enrichment, rotation and organizational citizenship behavior, while motivation was partially mediating the relationship between job rotation and counterproductive work behavior. This study enhances the existing literature of job design and contributes to research by finding how job design influences the OCB \& CWB.
\end{abstract}

Keywords: Job Enlargement, Job Enrichment, Job Rotation, Motivation, Organizational Citizenship Behavior, Counterproductive Work Behavior

\section{Introduction}

The work plan is an agreement or a reorganization aimed at reducing and overcoming job disruptions and recurring staff recurring. Programs related to task management began to establish scientific management approaches in the 1990s. Frederick Taylor is a well-known theorist, he writes the principles of scientific management. He believes that the job arrangement has set the task, task and responsibility of the task to be done. The purpose of this work arrangement is to promote job satisfaction and achievement by changing the content and process of a specific job so that employees can avoid getting tired (Taylor, 2004). It is assumed that salary is the most important factor to encourage employees. But many studies show that job design is a major influence on workers' incentives. Therefore management needs to consider how to organize work that affects the motivation and efficiency of the staff. The three types of job design are: i. Workplace refinement. Expansion of work and rotation in the workplace has significant implications for labor productivity. So managers should find ways to create jobs (Siruri \& Muathe, 2014). Competition costs and large increases in production are the reason for reducing, reducing costs and restructuring; so that the staff of the organization has to do a lot of work before adding more debt to its obligations in the form of expanded, refined and rotational work (Sverke \& Hellgren, 2001). Well-designed work helps to achieve two main goals: to get timely and effective employment, as well as motivation and hindrances to staff. If the workplace is well organized, it will benefit both business and labor. Poorly designed work leads to an inability to get a job on time and on a regular basis. Nor does he encourage unfortunate employees on his job. Even though the staff are competent and productive, they are disappointed, disappointed, and disappointed in the work that was designed to be poorly done (Borman, 2004). It is essential to create an enabling environment that is not only suitable for organization processes, but also for people who work in it because they are the assets of the organization. Administrators use different design methods that allow administrators to achieve desired results through motivation and employee satisfaction. Management focuses on aspects of work that meet the organization's goals. Thus, when designing a job design, they must find what is essential to work and staff (Garg \& Rastogi, 2006). The design of this work has three main elements: increasing the task of increasing the work and shifting tasks. 


\section{Literature Review}

Job Enlargement: Expanding the labor force means increasing the scope of work by expanding the scope of the task. On the contrary, officials who repeated the same steps for each product carried out different tasks within one unit. Top management always believes that competitive advantage is always the result of much in the department. For this reason, almost all organizations to cope with future challenges are tending to hire staff to implement different types of tasks efficiently. It is estimated that work, routine, boring, and lack of motivation are the reasons why expanding work is used as a way to reduce boredom in the workplace and increase employee motivation and job satisfaction. After analyzing the data collected from responses 534 by explaining and analyzing employment statistics, expansion of involvement was linked to the negative motivation, job satisfaction and commitment of the government in Pakistan. Employed staff has been widened by frustration and its predecessor starts to decline. This work has made staff feel that the organization owns them and considers them an integral part of the organization whose performances are thus enhanced. This shows that productivity is increased by increasing the level of satisfaction and satisfaction that is enhanced by expanding the job by creating a variety of skills in them and giving them a sense of ownership in the organization (Saleem et al., 2012). Job Balance is extremely important for the sustainability of the business because, after achieving a balance between work and private life, meeting workers, and working well. Expanding the workplace and increasing the workplace are two of the major workplace designs designed to motivate employees and create a level of employee satisfaction, which is useful for achieving a balance between work and business sustainability (Sushil, 2014). This expanded work has a positive effect on employee motivation, as staff perceive that they will pay the price to make a specific effort to try to perform well in the organization, providing additional duties. The performance of this staff is enhanced when accompanied by any reward.

Job Enrichment: enriching at work, increasing self-sufficiency, self-control, and self-confidence of workers, which adds to their performance (Saleem, Shaheen and Saleem, 2012)? Education is the most important determinant of resilience to increased labor force. Young employees have failed to create jobs, while older employees are unwilling to accept refined jobs (Colin and Raubolt, 1975). Enhancement of employment creates a method in the mind of an employee to understand what their work, their desire, their work, and their form of satisfaction are (McLean and Sims, 1978). Improvements in the workplace increase employee motivation and productivity, and it also leads to increased employee commitment to achieving goals (Dost \& Khan, 2012). A study has been conducted to resolve the issue with Nigerian bankers. The samples were collected from 180 marketing executives was conducted t-tests of these data and the results show that the authority, control, accountability and diversity of the work related to employment, increasing motivation, marketing director demotivation to work in the banking sector in Nigeria is in a better position to make a The (Uduji, 2013). There is an important link between job refinement, expansion and balance of professional life, which enhances employee productivity and enhances productivity, contributes to the sustainability of this globally competitive business. On the other hand, it is beneficial to improve the balance of work life of employees who are so important for staff to have a good time for relaxing with their families (Sushil, 2014).

Job Rotation: Job rotation is a method in which a person moves through a schedule designed to broaden his exposure and enhance their skills. Truly turning jobs helps to become more competitive, staff organizations are motivated by the skillfulness and ability to carry out all tasks that enhance their effectiveness. Using this tool, the foundation of the talent it grows, and employees can move from strength to strength, creating a winning situation for yourself and the company. Ortega (2001) argues that the rotation of this operation, compared to this skill, can improve the organization's learning in this circumstance, when fewer staffs have been trained on the task. Job rotation gives staff the opportunity to acquire new skills and to master the new ways of accomplishing tasks and approving new procedures. This motivates many more, satisfied, and fulfilling their obligations because they believe in trust, leadership and pay attention to reducing boredom and increasing the interests of workers. After getting rid of boredom and becoming more interesting and hardworking, employees are more likely to work towards this task (Naqvi et al., 2013). The positioning of the workplace has a positive impact on employee motivation because the staff understands that they will be rewarded for doing a good job, so try to work well in the organization, learn new skills and apply those skills. Task assigned. Increase productivity and improve organizational performance. Management should focus on the design of a job that is accompanied by a certain motivation and awards for employees (Onimole, 2015). 
Motivation: Motivation is a necessity or a desire that makes an act. Motivation in turn means that guarantees, motivations and incentives are limited to actions or processes of reason. Motivation that is defined as such an act of process that gives the motivation that prompts a person to take action. In many cases, the motivation comes from a number of requirements that lead to behavior that leads to some sort of rewarding reward and external inherent reward. Shank, and even (2007), Motivation is the result of a mental process, (Mitchell, 1982), and many studies have demonstrated a performance-driven, climate-enhanced performance that enhances the productivity of staff and organizations (Brown \& Leigh, 1996). Individuals who are led to a course of motivation are attention, direction, intensity, and persistence of elemental behavior. Two Points of Incentives are: a) cash prizes; and ii) non-cash prizes, as the person who gets to perform their duties in the workplace. град outside the frame, include other factors, rather than monetary conditions, e.g., job expansion, enriching work, and job rotation, which keeps employees interested and does not feel part of the company at all. This practice, the organization is influenced by the many factors that are motivated are the most important factors. The work of the staff in the organization is driven by the necessary or external reward, so if the company employee is more motivated, the result of the company's activities also represents the representative (Ahmad, Wasay, \& Jhandir, 2012). Motivation is the most important element for all organizations that achieve excellence, whether they are public or private. Because employees who are motivated to work well lead to increased organizational achievement and achievement. Organizations that do not discourage focused employees cannot increase productivity and achieve organizational goals. To keep the world competitive in motivating the staff of the key factors (Chintallo \& Mahadeo, 2013).

Organizational Citizenship Behaviour: Murphy says "performance is synonymous with attitudes and behaviors to achieving the organization's goals." Check out the performance is more attractive. The behavior of this practice is divided into two types, one type is that the behavior that is directly linked to the performance, results and objectives of the organization is clearly defined, can be observed and measured. Another characteristic of behavior is not clearly defined in the organization's system of rewards and punishments, but has a direct effect on the organization's performance, which is called behavior of civilian behavior. It has been found that OCB has been linked positively with the productivity of the unit and customer satisfaction (Podsakoff, White, Podsakoff and Blume, 2009). The importance of attitudes determines me. The negative attitudes in the workplace and the behavior of the citizenship of the organization are so high that the relationship between these two factors is examined in the geographical context of Pakistan and has been found to have a negative relationship between them (UllahBukhari and Ali, 2009). Researchers also noted that staff contacts ensure the health of the organization. So, by improving the organizational attitude of the organization and reducing the bad behavior in the organization's work health (Frost \& Koys, 2011). Satisfied with the employment of high employee Zadarzhanost and low absentee have a positive effect on organizational attitudes and labor disputes, and job congestion as a negative consequence of OCB (Signs \& Pradhan 2013). Organizational civil behavior can be challenged by staff with respect and acceptance (Peyrat-Guillard \& Glinska-Newes, 2014).

Counterproductive Work Behavior: An employee's behavior, which contradicts the legitimate interests of an organization, is called anti-aggressive behavior. This behavior affects organizations and even people working within the organization. Anti-manufacturing behaviors are becoming a constant threat to the organization. There are two types of costs associated with this type of behavior: i) financial expenses, including loss of productivity, claims and reparations, ii) social costs, including dissatisfaction with the work, mental and physical injury. A leading force behind the work attitude may be the lack of training and education, staffing, and a change in their lives, and a number of other factors. Such attitudes can be handled by applying strategies in human resources while selecting, examining their integrity and personality. These types of problems can be avoided by creating and providing balance and sense of organization's sensitivity among staff. Staff attitude is very important to the success of the company in this era. Management should focus on finding the cause of stress in the workplace, and to implement strategies to eliminate employee stress (Aftab and Javed, 2012). Data collected from responses working in 304 UK were analyzed using statistical techniques and found conflicts and threats positively affecting negative attitudes (Boddy, 2014). The successful staff motivates the staff by having more employees, their frustrations, other organizations. Unhappy employees tend to tend to work in bad jobs. Break the rules, long breaks and slow work. Management should focus on reducing this behavior in the organization to maintain and improve employee performance and increase employee motivational incentives to overcome this problem arising from the 
negative attitude of the workforce (Bratu, 2015). The world of competitive business today has become a highly-coveted place where the survival of the forest is physically and physically unique. This means that resources should be used to replace the competition, optimism and excellence in all directions.

\section{Research Objectives}

- To investigate the impact of job design on organizational citizenship behavior.

- To discover the effect of job design on counterproductive work behavior.

- To investigate the mediating role of motivation between job design and organizational citizenship behavior.

- To investigate the mediating role of motivation between job design and counterproductive work behavior.

\section{Conceptual Framework}

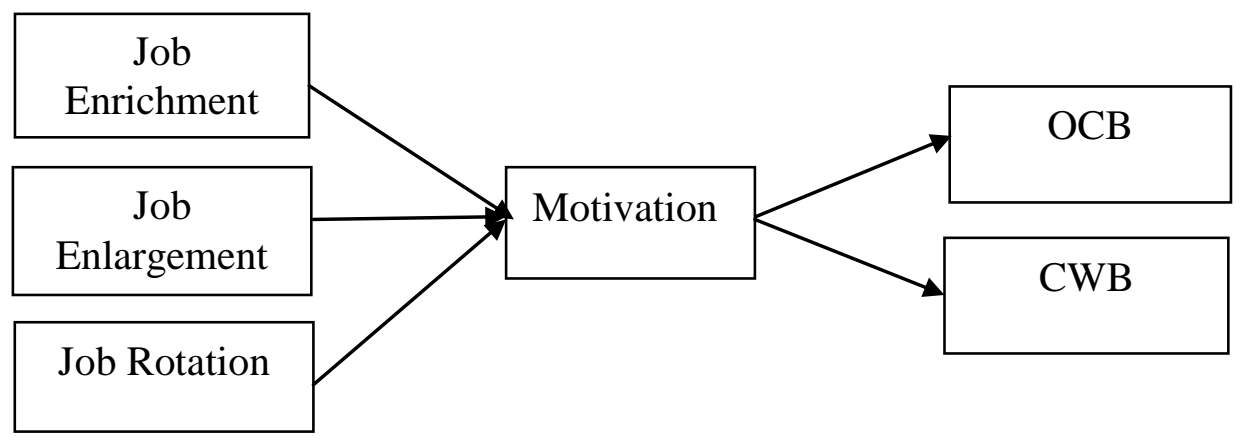

\section{Hypothesis:}

H1: Job enlargement is significantly associated with organizational citizenship behaviour.

H2: Job enrichment is significantly associated with organizational citizenship behaviour.

H3: Job rotation is significantly associated with organizational citizenship behaviour.

H4: Job enlargement is significantly associated with counterproductive work behaviour.

H5: Job enrichment is significantly associated with counterproductive work behaviour.

H6: Job rotation is significantly associated with counterproductive work behaviour.

H7: Motivation mediates the relationship between job enlargement and organizational citizenship behaviour.

H8: Relationship between job enrichment and organizational citizenship behaviour is mediated by motivation.

H9: Motivation mediates the relationship between job rotation and organizational citizenship behaviour.

H10: Relationship between job enlargement and counterproductive work behaviour is mediated by motivation.

H11: Motivation mediates the relationship between job enrichment and counterproductive work behaviour. H12: Relationship between job rotation and counterproductive work behaviour is mediated by motivation.

\section{Methodology}

Participants: The participation population for the study comprised of different banks of Faisalabad (Pakistan). Participants of the study were frontline managers of the banks. Total distributed questionnaire among the individuals were 200 , out of which 170 responses were received. The high turnover of almost $85 \%$ is attributed to the involvement of respondent. The unit of analysis was the individuals who responses to the survey.

Measures: In our survey, responses were rated on the Likert Scale format, with answers rating from 1 to 5 (1 $=$ Strongly Disagree to $5=$ Strongly Agree). To measure the organizational citizenship behavior (OCB), we used OCB measure developed by Podsakoff (2006). Scale developed by Bennett \& Robinson (2002) were used to measure the CWB. Motivation was measured by using the scale of Mckinsey (2002). Job enlargement, job enrichment and job rotation were measured by using the scale used by Ali Muhammad (2004), Venith \& Indradevi (2015) and Kokala \& Gomathi (2015) respectively. These scales were modified according to the 
objectives of the study. Respondents were assured of confidentiality to guarantee the fairness of responses. Respondents were also provided with full explanation of the questionnaire.

Methodology: Following the collection of data, all the data received in the form of individuals responses was punched and a set of analyses were applied i.e. Correlation, regression analysis and sobel test etc to investigate the hypothesis by using the SPSS (version 21.0).

\section{Results}

We use the linear regression model to analyze the simple effect with the help of SPSS, micro program "process". Steps suggested by Muller, Judd and Yzerbyt were followed in order to test the hypothesis (Muller, Judd, \& Yzerbyt, 2005). Multivariate two level model No. 4 sobel test was used for testing the hypothesis with the exploratory variables (X), motivation as mediator (M) while OCB \& CWB as Dependent Variable (Y). In the second row of table No. 04 in appendix, it is shown that direct effect of job enlargement on the organizational citizenship behavior is significant and positive with the value of $0.587, \mathrm{p}<.01$ ( $\mathrm{H} 1$ accepted). Indirect effect of job enlargement on the organizational citizenship behavior is also significant with the values of $0.146, \mathrm{p}<.01$. On introducing the motivation as mediator, higher value of total effect $(0.732, p>.01)$ than direct effect and increase in the significance level showed that motivation has partially mediated the relationship of job enlargement and organizational citizenship behavior which furnishes support for acceptance of H7. Third row of above table shows that direct effect of job enrichment on the organizational citizenship behavior is significant and positive with the value of $0.632, \mathrm{p}<.01$ (H2 accepted). Indirect effect of job enrichment on the organizational citizenship behavior is also significant with the values of $0.423, p<.01$. On introducing the motivation as mediator, higher value of total effect $(1.055, \mathrm{p}<.01)$ than direct effect and increase in the significance level indicated that motivation was partially mediating the relationship of job enrichment and organizational citizenship behavior. It provides support for acceptance of H8.

In the fourth row of above table, it is shown that direct effect of job rotation on organizational citizenship behavior is significant but negative with the value of $-0.229, \mathrm{p}<.01$ (H3 accepted). Indirect effect of job rotation on the organizational citizenship behavior is also significant with the values of $0.615, \mathrm{p}<.01$. On introducing the motivation as mediator, higher value of total effect $(0.386, p>.01)$ than direct effect and increase in the significance level showed that relationship of job rotation and organizational citizenship behavior has turned positive from negative i.e. 0.615, $\mathrm{p}<.01$ which indicates that motivation is partially mediating the relationship of job rotation and organizational citizenship behavior providing support for acceptance of H9. Last row of above table shows that direct effect of job rotation on counterproductive work behavior is significant but positive with the value of $0.835, \mathrm{p}<.01$ (H6 accepted). Indirect effect of job rotation on the counterproductive work behavior is negative but significant with the value of $-0.528, \mathrm{p}<.01$. On introducing the motivation as mediator, lower value of total effect $(0.307, p>.01)$ and decrease in the significance level showed that motivation has partially mediated the relationship of job rotation and counterproductive work behavior which provides support for acceptance of H12.

Analyses of Simple Effect of Job Enlargement, Job Enrichment \& CWB: In order to test the hypothesis No. $4 \& 5$ it revealed that there was a significant relationship between job enlargement and CWB (H4 accepted) while insignificant relation was found between the job enrichment and CWB (H5 rejected). To find the mediating effect of motivation in hypothesis No.10 \& 11, multivariate two levels model 4 sobel test was used with the exploratory variables job enlargement and job enrichment (X), motivation as mediator (M) and counterproductive work behavior as Dependent Variable (Y). It was observed that in the case of job enlargement and counterproductive work behavior, value of PYM was insignificant with the value of 0.204, $p>.05$. Because to this, value of indirect effect PYM.PMX was also insignificant with the value of 0.113 hence there was found no mediation between the job enlargement and counterproductive work behavior. Similarly in the case of job enrichment and counterproductive work behavior, value of PYM was insignificant with the value of $-0.145, p>.05$. Hence indirect effect PYM.PMX was also insignificant with the value of -0.166 . Change in $\mathrm{R}^{2}$ also indicted no change in the strength of model after introducing the motivation as mediator which indicated no mediation between the job enrichment and counterproductive work behavior and provided support for rejection of $\mathrm{H} 10$ \& $\mathrm{H} 11$. 
Discussion: The objective of the study was to analyze the impact of job enlargement, job enrichment and of job rotation on the organizational citizenship behavior and counterproductive work behaviors of the frontline managers working in the banking sector of Faisalabad. Mediating effect of motivation on these relations was also tested in this study. Data were collected from the banks across the Faisalabad. After analyzing the collected data through statistical techniques, impact of job design in the context of job enlargement, enrichment and job rotation was examined on the organizational citizenship behavior and counterproductive work behavior. In the case of organizational citizenship behavior, value of $\mathrm{R}^{2}$ showed the strength of model is $77.2 \%$. It implies that $77.2 \%$ variance is shared by these independent variables in the dependent variable i.e. OCB. It was also observed that job enlargement and job enrichment were positively and significantly associated with the OCB with the values of 0.587 and 0.632 respectively at $p<0.01$ while the job rotation was found significant but having negative impact on the OCB with the value of -0.229 at $\mathrm{p}<0.05$. Hence H1, H2 and H3 were accepted (Table No. 02 in appendix). When these three independent variables were examined for their relationship with counterproductive work behavior, value of $\mathrm{R}^{2}$ showed that the strength of model is $16.8 \%$. It implies that $16.8 \%$ variance is shared by job enlargement, enrichment and rotation in the dependent variable i.e. CWB. It was also observed that job enlargement was negatively and significantly associated with the CWB with the values of -0.564 at $\mathrm{p}<0.01$. Job enrichment was found insignificant having negative relationship with Counterproductive work behavior with the value of -0.216 . Job rotation was having positive relationship with $\mathrm{CWB}$ with the value of $0.835, \mathrm{p}<0.01$. Hence $\mathrm{H} 4$ and $\mathrm{H} 6$ were accepted while $\mathrm{H} 5$ was rejected (Table No. 03 in appendix).

Mediation effect of the motivation was also checked one by one on OCB and CWB. It was found that in case of job enlargement, motivation partially mediated the relation between job enlargement and OCB. In case of job enrichment motivation was also found partially mediating the relationship. When this relation is checked with job rotation, it is revealed that motivation has also partially mediated the relation between job rotation and organizational citizenship behavior. When the mediation effect was checked for CWB, it was observed that there were no mediation in the relationships of job enlargement and job enrichment, while the motivation partially mediated the relationship of job rotation and counterproductive work behavior. Hence H7, H8, H9 and H12 were accepted while H10 \& H11 were rejected. It was observed that job enlargement was positively and significantly associated with the organizational citizenship behavior with the value of 0.587 . After introducing the motivation as mediator, this value was increased from 0.587 to 0.732 . Job enrichment was significantly and positively associated with organizational citizenship behavior with the value of 0.632 but the mediator i.e. motivation has increased this value from 0.632 to 1.055 . Job enlargement and job enrichment have positive and significant relation with OCB. Increase in organizational citizenship behavior causes employee's job satisfaction. As a result, CWB decrease and they began to perform well which helps in achieving the organizational goals.

Job rotation was found to be significantly and negatively associated with organizational citizenship behavior. But after introducing the motivation as mediator, this negative value was turned positive from negative which showed the partial mediation of motivation. Job enrichment is vertical increase in the duties. It means that the employees are assigned duties to perform which are meant for higher posts. Insignificance of job enrichment can be due to enriching the jobs of such persons who have not the caliber, skills and abilities to handle the enriched job or it is also possible that the respondents who have responded to job enrichment statements have never faced enrichment in their jobs and their responses can be result of biasness. Job rotation was significantly and positively associated with counterproductive work behavior with the value of 0.835 and the this relation was also partially mediated by the motivation and motivation decreases the CWB from 0.835 to 0.307 while in cases of job enlargement and job enrichment there were no mediation. Findings revealed that employees take job enlargement and job enrichment as source of removal of boredom, repetitive tasks. Due to charging additional tasks, their jobs become interesting and challenging. Employees take additional task as opportunity to increase their skill and abilities and also consider it helpful in improving their growth opportunities. As a result organization citizenship behavior increases and counterproductive work behavior decreases. While in the case of job rotation, it was observed that job rotation was negatively associated with OCB and positively associated with CWB which showed that employees do not like job rotation but when they were motivated by the management their negative respond to job rotation turned into positive. 
In job rotation people are rotated from department to department for performance of different types of jobs in order to learn and improve their skills and abilities and to perform on behalf of others in contingencies and to reduce the hiring cost of new employees. Purpose of the job rotation is to improve the skills of employees but sometimes employees become demotivated and dissatisfied with their job. Resultantly, their organizational citizen ship behavior decreases and counterproductive work behaviors increases. Negative effect of job rotation on the OCB and positive effect of job rotation on the CWB can be due to the reasons that employees become dissatisfied due to continuous move from their basic job to perform other jobs in the same organization. On the other hand, there are number of banking employees having degrees other than MBA or M.Com (concerned with the fields of accounts and finance) so lack of background knowledge become the reason of negatively impact of job rotation on organizational citizenship behavior and positive impact on counterproductive work behaviors which is in confirmation of "Ortega" that job rotation indeed can enhance the learning abilities of the employees in an organization but there must be a little information about the perform to be assigned otherwise employees think that to shift to new job sometimes gives them stress (Ortega, 2001).

According to best of my knowledge and resources, there is no literature available about the impact of job enlargement, job enrichment and job rotation on the organizational citizenship behavior and counterproductive work behaviors. This study has explored this relationship and contributed towards the literature by examining and finding the impact of job enlargement, job enrichment and job rotation on the organizational citizenship behavior and counterproductive work behavior. Findings of this study are also in confirmation of social exchange theory that when employees feel that their organization is caring for their personal growth, advancement and development in performance of their tasks, they feel satisfied and happy with the organization. This way they reciprocate by demonstrating positive attitude and behavior which benefits the organization to achieve the organizational goals.

\section{Conclusion}

To explain and provide the valuable insight to the studies of job enlargement, job enrichment and job rotation, we have achieved our objectives by investigating the impact of job enlargement, enrichment and rotation on OCB and CWB and how the motivation mediates theses relationship. There is no previous official statistics available for the elements of job design i.e. job enlargement, job enrichment and job rotation with mediating effect of motivation on the organizational citizenship behavior and counterproductive work behavior. This study mainly focuses on the job enlargement, job enrichment, job rotation, OCB \& CWB. Results revealed positive and significant relationship between job enlargement and of job enrichment on the OCB while negative and significant relationship of job rotation on the OCB. It was also revealed that there is a negative and significant relationship between job enlargement and CWB, negative but insignificant relationship between job enrichment and CWB while positive and significant relationship between the job rotation and CWB. On the other hand, motivation partially mediates the relationship between job enlargement, job enrichment, job rotation and organizational citizenship behavior, respectively. There were no mediation between job enlargement, job enrichment and counterproductive work behavior, respectively while motivation was found partially mediating the relationship between job rotation and counterproductive work behavior.

Limitations: No research is a $100 \%$ perfect. This research involves studying human behavior and we all know that behavior varies from person to person because there are different thought processes in each of us. It is quite possible a factor that motivates one person cannot motivate the other person. This survey was questionnaire based and responses were taken from the different types of people from different backgrounds working in banks. It was difficult to work out a certain pattern of study. Some questions also led the respondents to bias, which might be because, some people think of certain questions in a personal manner and start concealing or overstating information. Limited sample size is also limitation of this study so the finding cannot show the true and fair picture for all the employees working in the banking sector of Pakistan. Sample was taken from the banks of Faisalabad so this study cannot be generalized for all the banks of Pakistan. Banking environment being so busy these days, it was hard to find people who wanted to devote their time sincerely in helping this research. 


\section{References}

Aftab, H. \& Javeed, A. (2012). The Impact of Job Stress on the Counter-productive Work Behavior (CWB) A Case Study from the financial Sector of Pakistan. Interdisciplinary Journal of Contemporary Research in Business, 4(7), 590.

Baron, R. M. \& Kenny, D. A. (1986). The moderator-mediator variable distinction in social psychological research: Conceptual, strategic, and statistical considerations. Journal of personality and social psychology, 51(6), 1173.

Boddy, C. R. (2014). Corporate psychopaths, conflict, employee affective well-being and counterproductive work behaviour. Journal of Business Ethics, 121(1), 107-121.

Borman, W. C. (2004). The concept of organizational citizenship. Current directions in psychological science, 13(6), 238-241.

Bowling, A. (1997). Data collection methods in quantitative research: questionnaires, interviews and their response rates. Research methods in health: Investigating health and health services, 3, 257-272.

Bratu, S. (2015). Are Organizational Citizenship Behaviors (OCBS) Really Positively Associated with Measures of Organizational Effectiveness? Analysis and Metaphysics, 14, 87-93.

Brown, S. P. \& Leigh, T. W. (1996). A new look at psychological climate and its relationship to job involvement, effort, and performance. Journal of applied psychology, 81(4), 358.

Collins, D. C. \& Raubolt, R. R. (1975). A Study of Employee Resistance to Job Enrichment. Personnel Journal, $54(4), 232-235,248$.

Daft, R. (2006). Organization theory and design: Cengage learning.

Dahie, A. M. \& Ali, A. A. Teacher Motivation and School Performance, the Mediating Effect of Job Satisfaction: Survey from Secondary Schools in Mogadishu.

Dalal, R. S. (2005). A meta-analysis of the relationship between organizational citizenship behavior and counterproductive work behavior. Journal of applied psychology, 90(6), 1241.

Dash, S. \& Pradhan, R. K. (2013). Determinants \& Consequences of Organizational Citizenship Behavior: A Theoretical Framework for Indian Manufacturing Organisations. International Journal of Business and Management Invention, 3(1), 17-21, 2319, 8028.

Dost, M. K. B. \& Khan, H. J. (2012). Job Enrichment Causes High Level of Employee Commitment During the Performance of their Duties: A Behavioral Study. Arabian Journal of Business and Management Review (Oman Chapter), 1(10), 95.

Dost, M. K. B. \& Saleem, S. (2012). The job enrichment causes high level of employee commitment during the performance of their duties: a behavioral study from Pakistan. Arabian Journal of Business and Management Review (Oman Chapter), 1(9), 135.

Frost, B. \& Koys, D. J. (2011). Organizational Citizenship Behavior, Employer Support, and Unit-Level Outcomes: A Longitudinal Study.

Garg, P. \& Rastogi, R. (2006). New model of job design: motivating employees' performance. Journal of management Development, 25(6), 572-587.

McLean, A. \& Sims, D. (1978). Job enrichment from theoretical poverty: The state of the art and directions for further work. Personnel Review, 7(2), 5-10.

Mitchell, T. R. (1982). Motivation: New directions for theory, research, and practice. Academy of management review, 7(1), 80-88.

Mohammad, J., Habib, F. Q. \& Alias, M. A. (2011). Job satisfaction and organisational citizenship behaviour: An empirical study at higher learning institutions. Asian Academy of Management Journal, 16(2), 149165.

Mohan, K. \& Gomathi, S. (2015). The Effects of Job Rotation Practices on Employee Development: An Empirical Study on Nurses in the Hospitals of Vellore District. Mediterranean Journal of Social Sciences, 6(1), 209.

Naqvi, S. R., Ishtiaq, M., Kanwal, N. \& Ali, M. (2013). Impact of job autonomy on organizational commitment and job satisfaction: The moderating role of organizational culture in fast food sector of Pakistan. International Journal of Business and Management, 8(17), 92.

Ortega, J. (2001). Job rotation as a learning mechanism. Management Science, 47(10), 1361-1370.

Peyrat-Guillard, D. \& Glinska-Newes, A. (2014). I Respect You and I Help You: Links Between Positive Relationships at Work and Organizational Citizenship Behaviour. Journal of Positive Management, 5(2), 82. 
Podsakoff, N. P., Whiting, S. W., Podsakoff, P. M. \& Blume, B. D. (2009). Individual-and organizational-level consequences of organizational citizenship behaviors: A meta-analysis. Journal of applied psychology, 94(1), 122.

Podsakoff, P. M., Ahearne, M. \& MacKenzie, S. B. (1997). Organizational citizenship behavior and the quantity and quality of work group performance. Journal of applied psychology, 82(2), 262.

Podsakoff, P. M., MacKenzie, S. B. \& Organ, D. (2006). Organizational citizenship behavior: Its nature, antecedents, and consequences: Sage Publications, Thousand Oaks, CA.

Saleem, S., Shaheen, W. A. \& Saleem, R. (2012). The impact of job enrichment and job enlargement on Employee satisfaction keeping employee performance as Intervening variable: a correlational study from Pakistan. Kuwait Chapter of the Arabian Journal of Business and Management Review, 1(9), 145.

Shanks, N. H. \& Dore, A. (2007). Management and motivation. Fonte: http://www. jblearning. com/samples X, 76373473.

Shaughnessy, J. J. Z., Zechmeister, E. B., Martínez, J. S. G. \& Ericka, B. D. B. (2007). Métodos de investigación en psicología: McGraw-Hill.

Siruri, M. M. \& Muathe, S. (2014). A Critical Review of Literature on Job Designs in Sociotechnical Systems.

Sushil, S. (2014). Role of Job Enrichment and Job Enlargement in Work Life Balance. Global Journal of Finance and Management, 6(3), 239-244.

Sverke, M. \& Hellgren, J. (2001). Exit, Voice and Loyalty Reactions to Job Insecurity in Sweden: Do Unionized and Non-unionized Employees Differ? British Journal of Industrial Relations, 39(2), 167-182.

Taylor, F. W. (2004). Scientific management: Routledge.

Turnipseed, D. L. \& Rassuli, A. (2005). Performance Perceptions of Organizational Citizenship Behaviours at Work: a Bi-Level Study among Managers and Employees. British Journal of Management, 16(3), 231244.

Uduji, J. I. (2013). Job Enrichment: A Panacea to the Problem of the Demotivated Marketing Executives in the Banking Industry in Nigeria. California Management Review, 16, 57-71.

Ullah Bukhari, Z. \& Ali, U. (2009). Relationship between organizational citizenship behavior \& counterproductive work behavior in the geographical context of Pakistan. International Journal of Business and Management, 4(1), 85.

\section{Appendix}

Table 1: Correlation Matrix

\begin{tabular}{llllllll}
\hline Sr. No. & Correlation & $\mathbf{1}$ & $\mathbf{2}$ & $\mathbf{3}$ & $\mathbf{4}$ & $\mathbf{5}$ & $\mathbf{6}$ \\
\hline 1 & Job Enlargement & 1 & & & & & \\
2 & Job Rotation & $.394^{* *}$ & 1 & & & & \\
3 & Job Enrichment & $.560^{* *}$ & $.585^{* *}$ & 1 & & & \\
4 & Motivation & $.612^{* *}$ & $.534^{* *}$ & $.550^{* *}$ & 1 & & \\
5 & OCB & $.632^{* *}$ & $.342^{* *}$ & $.545^{* *}$ & $.631^{* *}$ & 1 & \\
6 & CWB & $-.304^{* *}$ & $.155^{*}$ & $-.154^{*}$ & $-.153^{*}$ & $-.297^{* *}$ & 1 \\
& $* * \mathrm{p}<0.01 * \mathrm{p}<0.05$ & & & & & & \\
\hline
\end{tabular}


Table 2: Regression Analysis of Organizational Citizenship Behavior

\begin{tabular}{|c|c|c|c|c|c|c|}
\hline Model & $\mathbf{R}$ & R Square & Adjusted & RStd. Error & the Esti & \\
\hline 1 & 881 & .776 & .772 & . 30045 & & \\
\hline Model & & Unstandardiz & ed Coefficients & Standardized & $\mathbf{t}$ & Sig. \\
\hline & & B & Std. Error & Beta & & \\
\hline & ment & .594 & .048 & .704 & 12.415 & .000 \\
\hline & & -.100 & 051 & -.089 & -1.951 & .053 \\
\hline Jol & nent & .371 & .091 & .262 & 4.068 & .000 \\
\hline
\end{tabular}

Table 3: Regression Analysis of Counterproductive Work Behavior

\begin{tabular}{|c|c|c|c|c|c|c|}
\hline Model & $\mathbf{R}$ & R Square & Adjusted & RStd. Error o & the Esti & \\
\hline 1 & .428 & .183 & .168 & 1.00877 & & \\
\hline Model & & Unstandardize & ed Coefficients & $\begin{array}{l}\text { Standardized } \\
\text { Coefficients }\end{array}$ & $\mathbf{t}$ & Sig. \\
\hline & & B & Std. Error & Beta & & \\
\hline Job Enl & nent & -.597 & .161 & -.403 & -3.716 & .000 \\
\hline Job Ro & & .677 & .172 & .341 & 3.929 & .000 \\
\hline Job EnI & ent & -.118 & .306 & -.047 & -.386 & .700 \\
\hline
\end{tabular}

Table 4: Analyses of Simple Effect for OCB \& CWB

\begin{tabular}{|c|c|c|c|c|c|c|c|}
\hline $\begin{array}{l}\text { Dependent } \\
\text { variable }\end{array}$ & Mediator & Independent & $\mathbf{P}_{\text {mx }}$ & PyM & $\begin{array}{l}\text { Direct } \\
\left.\text { effects ( } P_{Y X}\right)\end{array}$ & $\begin{array}{l}\text { Indirect } \\
\text { effects } \\
\left(\text { РYM Р }_{M X}\right)\end{array}$ & $\begin{array}{l}\text { Total } \\
\text { effects } \\
\left(P_{Y X}+P_{Y M}\right. \\
\text { PMX) }_{M X}\end{array}$ \\
\hline OCB & Motivation & Job Enlargement & $0.555(.000)$ & $0.262(0.000)$ & $0.587(.010)$ & $0.146^{* *}$ & $0.732^{* *}$ \\
\hline OCB & Motivation & Job Enrichment & $1.145(.000)$ & $0.369(.000)$ & $0.632(.012)$ & $0.423^{* *}$ & $1.055^{* *}$ \\
\hline OCB & Motivation & Job Rotation & $0.682(.000)$ & $0.903(.000)$ & $-0.229(.003)$ & $0.615^{* *}$ & $0.386^{* *}$ \\
\hline CWB & Motivation & Job Rotation & $0.681(.000)$ & $-0.774(.000)$ & $0.835(.000)$ & $-0.528^{* *}$ & $0.307^{*}$ \\
\hline
\end{tabular}

$\mathrm{N}=170 * \mathrm{P}<.05 * * \mathrm{P}<.01$

Where $\mathrm{P}_{\mathrm{MX}}$ refers to paths from independent variable to the mediator (motivation) and $\mathrm{P}_{\mathrm{YM}}$ refers to paths from the mediator to the outcome variable. PYX is the path from X (independent variable) to Y (dependent variable) which is called direct effect of independent variable on the dependent variable. PYM.PMX indicates indirect effect while PYX+PYM. PMXis total effect of X (independent variable) on Y (dependent variable) in the presence of mediator (motivation). 